\title{
Contabilidade Pública como instrumento de previsão do Índice de Desenvolvimento Humano na dimensão Renda para os municípios do Estado do Paraná
}

\begin{abstract}
Jorge Eduardo Scarpin
Doutorado em Ciências Contábeis pela Faculdade de Economia, Administração e Contabilidade da Universidade de São Paulo - FEA/USP Rua Reitor Strotmann, 36. Apto 303. Blumenau/SC E-mail: jorgescarpin@furb.br Valmor Slomskí
Doutorado em Ciências Contábeis pela Faculdade de Economia, Administração e
Contabilidade da Universidade de São Paulo - FEA/USP
Rua Monte Caseros, 302. Apto 53. São Paulo/SP
E-mail: valmor@usp.br
\end{abstract}

\section{RESUMO}

Este trabalho tem como objetivo analisar os fatores contábeis condicionantes do Índice de Desenvolvimento Humano Municipal (IDH-M) na dimensão renda nos municípios do Estado do Paraná. Inicia-se o estudo tratando de externalidades e bens públicos. Discorre-se também sobre a questão da Renda e Desenvolvimento Humano. Com base nesta fundamentação teórica, realiza-se uma pesquisa com variáveis contábeis e não contábeis para determinar a previsão do IDH-M na dimensão renda futuro. Por fim, mostra-se a análise da pesquisa, com o uso de regressões lineares e análise dos resultados para o estabelecimento de equações de previsão do IDH-M na dimensão renda futuro, com base em sete modelos estatisticamente determinados. A pesquisa revela diversas equações de previsão do IDH-M futuro na dimensão renda utilizando variáveis contábeis e não contábeis, com modelos que vão desde regressão simples até uma regressão múltipla com sete variáveis independentes. Conclui-se 0 trabalho apontando algumas considerações sobre a sua extensão para outros Estados da Federação.

Palavras-chave: IDH-M. Contabilidade Pública. Previsão.

\section{Public Accounting as an instrument to measure the impact of Human Development Index on income dimension in Paraná State, Brazil}

\section{ABSTRACT}

The present study seeks to contribute with the elaboration of new knowledges relative to the impact of public expenses on the formation of the local Human Development Index (local HDI) on income dimension. The theory of the study 
Contabilidade Pública como instrumento de previsão do Índice de Desenvolvimento Humano na dimensão Renda para os municípios do

Estado do Paraná

Jorge Eduardo Scarpin, Valmor Slomski

regards aspects of externalities and public assets and emphasizing the relationship of human development and income. The research of this study is an explain research, with quantitative and qualitative analysis. The instrument used on the research is the regression analysis, with multiple regressions using eighty seven independent variables, ten of them, non accounting variables and seventy seve accounting variables. To do all the necessary procedures to achieve the purposed objectives, seven statistical models were done. The report was concluded showing that local HDI has relation with financial and non-financial variables. At the end of the report, there are some possibilities of deepening of these subjects in new researches.

Key words: HDI. Public Accounting. Forecasting.

\section{INTRODUÇÃO}

No início da década de 1990, foi lançado pela ONU o Índice de Desenvolvimento Humano (IDH), índice este que se propõe a verificar o grau de desenvolvimento de um país utilizando alguns indicadores de desempenho. $\mathrm{O}$ IDH logo passou a ser a mais conhecida medida de desenvolvimento humano (Torres et al., 2003).

Valendo-se do sucesso do IDH, as Nações Unidas tornaram-se capazes de sinalizar aos governantes dos diversos países e regiões em desenvolvimento, a proposição de que buscar crescimento não é sinônimo exclusivo de fazer aumentar o produto interno bruto. No bojo desta questão tem sido possível constituir um considerável debate internacional a respeito de que, pelo menos, a melhoria das condições de saúde e educação da população deve também ser considerada como parte fundamental do processo de desenvolvimento.

A construção desse indicador de desenvolvimento reflete a estreita relação com os debates em torno da mensuração da qualidade de vida. A rigor, um indicador sobre esse tema se baseia na admissão de que a qualidade de vida não se resume à esfera econômica da experiência humana. A grande questão que se coloca quando se pretende avaliar o nível de prosperidade ou qualidade de vida de um país, região ou município, é como fazê-lo e quais os critérios verdadeiramente significativos para o desenvolvimento humano. 
Contabilidade Pública como instrumento de previsão do Índice de Desenvolvimento Humano na dimensão Renda para os municípios do

Estado do Paraná

Jorge Eduardo Scarpin, Valmor Slomski

Nos últimos quatrocentos anos, as cidades têm crescido e se modernizado, contribuindo para o desenvolvimento em suas regiões e de forma indireta ao mundo em geral. Nos dias de hoje, a cidade reflete parte de uma sociedade globalizada atuando como um ponto em uma rede de informações totalmente interligadas. Entretanto, qualquer que seja a aparência de uma cidade hoje ou em tempos passados, essa sempre formou o berço da civilização.

Sendo a cidade tão importante, é função do Estado garantir que seus cidadãos possam conviver da forma mais harmoniosa possível uns com os outros. Para isto, há a arrecadação de tributos (impostos, taxas e contribuições de melhorias) por parte do Estado junto aos cidadãos e o posterior gasto para a maximização do bem-estar da população. Em tese, quanto maior o gasto, maior o nível deste bem-estar.

O IDH, criado no início da década de 1990 para o Programa das Nações Unidas para o Desenvolvimento (PNUD) é uma contribuição para essa busca, e combina três componentes básicos do desenvolvimento humano: a longevidade, que também reflete, entre outras coisas, as condições de saúde da população, medida pela esperança de vida ao nascer; a educação, medida por uma combinação da taxa de alfabetização de adultos e a taxa combinada de matrícula nos níveis de ensino fundamental, médio e superior; a renda, medida pelo poder de compra da população, baseado no PIB per capita ajustado ao custo de vida local para torná-lo comparável entre países e regiões, através da metodologia conhecida como paridade do poder de compra (PPC);

Analisando-se o perfil do IDH-M (Índice de Desenvolvimento Humano Municipal) na questão renda e a possível contribuição da contabilidade pública no sentido de registrar adequadamente o nível dos gastos públicos, surge a seguinte questão de pesquisa: quais os fatores contábeis condicionantes do IDH-M na dimensão renda?

Para prover resposta à questão de pesquisa, este trabalho tem como objetivo analisar os fatores contábeis condicionantes do IDH-M na dimensão renda nos municípios do Estado do Paraná. 
Contabilidade Pública como instrumento de previsão do Índice de Desenvolvimento Humano na dimensão Renda para os municípios do

Estado do Paraná

Jorge Eduardo Scarpin, Valmor Slomski

Assim, com o presente estudo busca-se contribuir com a elaboração de novos conhecimentos relativos ao impacto dos gastos públicos na formação do Índice de Desenvolvimento Humano Municipal na dimensão renda, com o intuito de poder direcionar as políticas públicas, de modo que possam alocar seus recursos da forma mais eficiente possível, visando criar um município cada vez mais desenvolvido.

\section{REFERENCIAL TEÓRICO}

Para fundamentar a pesquisa deste trabalho, faz-se necessária uma ampla revisão da literatura existente a respeito do tema.

A revisão da literatura dar-se-á em duas frentes distintas. O primeiro tópico de estudo é sobre externalidades e bens públicos, que dará o suporte teórico para a pesquisa constante neste trabalho e a seguir, será abordada a relação entre renda e desenvolvimento humano.

\subsection{Externalidades e Bens Públicos}

A discussão sobre o papel da intervenção governamental na economia, para fins de alocação equitativa dos recursos da sociedade tem, como embasamento, a Teoria dos Bens Públicos para a justificativa da alocação dos recursos nacionais entre o setor público e privado, para fornecimento de parte de bens requeridos pela população. Essa teoria visa analisar a eficiência na utilização dos recursos pelo setor público.

A externalidade é definida por Pindyck e Rubinfeld (1994, p. 904) como sendo a "ação de um produtor ou consumidor que afete outros produtores ou consumidores, entretanto não levada em consideração no preço de mercado".

As externalidades podem surgir entre produtores, entre consumidores, ou entre produtores e consumidores. De acordo com Kon (1997, p. 35), "as externalidades positivas, representam as economias nos custos produtivos e os benefícios para os agentes que as usufruem, enquanto que as negativas ou deseconomias, se associam a prejuízos, aumentos nos custos, desvantagens", também chamadas de 
Contabilidade Pública como instrumento de previsão do Índice de Desenvolvimento Humano na dimensão Renda para os municípios do

Estado do Paraná

Jorge Eduardo Scarpin, Valmor Slomski

benefício externo (externalidade positiva) e custo externo (externalidade negativa). Em outras palavras, as externalidades negativas ocorrem quando a ação de uma das partes impõe custos sobre a outra, e as externalidades positivas, quando a ação de uma das partes beneficia a outra.

$\mathrm{Na}$ presença de externalidades, o interesse da sociedade em relação a um resultado de mercado vai além do bem-estar de compradores e vendedores do mercado, incluindo também o bem-estar das demais pessoas afetadas. Mankiw (2001, p. 208) afirma que "como compradores e vendedores negligenciam os efeitos externos de suas ações ao decidir quanto demandar ou ofertar, o equilíbrio de mercado não é eficiente na presença de externalidades". Isto significa que o equilíbrio de mercado não consegue maximizar o benefício total para a sociedade como um todo.

Dentre os mecanismos existentes para a correção da alocação ineficiente de recursos em um mercado provocado por uma externalidade encontram-se políticas públicas. Kon (1997) assinala que a intervenção governamental no sistema econômico, freqüentemente, tem como objetivo a criação, manutenção e aprimoramento de externalidades positivas, e a eliminação, correção e controle de externalidades negativas. $O$ fornecimento de bens e serviços públicos cria externalidades positivas para uma parcela da sociedade, representadas por economias de urbanização ou de aglomeração. No entanto, estas estão sujeitas a se transformarem em deseconomias quanto ultrapassarem um tamanho considerado "ótimo" de concentração urbana, levando à deterioração dos bens e serviços públicos. Mas a deterioração pode demorar mais ou menos tempo para se fazer sentir, pois cada tipo de bem ou serviço público apresenta uma capacidade ou limite, além do qual a interferência mútua entre os consumidores se torna notável e aumenta desproporcionalmente à oferta pelo governo. Mesmo no caso de "bens livres", ou seja, os fornecidos pela natureza, a ação humana pode aumentar a capacidade de sua utilização ou ultrapassar o limite de possível fruição.

As políticas públicas podem ser divididas em política de regulamentação e políticas baseadas no mercado. Na regulamentação, o governo pode solucionar 
Contabilidade Pública como instrumento de previsão do Índice de Desenvolvimento Humano na dimensão Renda para os municípios do

Estado do Paraná

Jorge Eduardo Scarpin, Valmor Slomski

uma externalidade tornando certos comportamentos exigidos ou proibidos, como, por exemplo, exigir que não se jogue resíduo tóxico em mananciais de água, ou fazendo leis de controle da poluição.

Além da regulamentação, o governo pode trabalhar com impostos ou incentivos privados, tributando as atividades que geram externalidades negativas e subsidiando aquelas que geram externalidades positivas.

Além destas ações públicas, há que se considerar que a eficiência do mercado está presente nos bens denominados de privados. Entretanto, existem diversos outros bens além dos bens privados, que são: bens públicos, monopólios naturais e recursos comuns.

Os bens públicos não são nem excluíveis nem rivais, ou seja, não se pode impedir as pessoas de desfrutar dos bens públicos, e um bem público pode ser desfrutado por várias pessoas sem prejuízo de nenhuma delas. Wonnacott e Wonnacott (1994, p. 104) afirmam que bem público puro "tem benefícios que não podem ser negados a ninguém, mesmo aos que não tenham pago pelo bem".

Medeiros (1999) cita três aspectos do uso do conceito de bem público. Primeiro, bem é uma palavra que inclui coisas não-materiais, como os serviços. Segundo, público não significa estatal. Essa diferença fica mais clara quando se menciona o terceiro aspecto: público diz respeito ao resultado do consumo do bem e não de sua produção. Não interessa, no exemplo, quem produziu as vacinas, mas quem foi vacinado. No entanto, no debate sobre justiça de alocação de recursos, é possível lançar a pergunta sobre quem deve produzir os bens públicos. Toda produção implica custos (econômicos e não-econômicos) para o produtor.

A produção de um bem público pode tanto ser feita por agentes públicos ou privados. Pindyck e Rubinfeld (1994, p. 878) defendem que "a produção de um bem público pelo governo é vantajosa porque este pode avaliar os impostos ou tarifas que deverão ser os responsáveis pelo pagamento de tal bem". Por sua vez, a alocação de recursos públicos na produção de um bem público é algo complexo, visto que, segundo Kon (1997, p.153), "os consumidores não revelarão suas preferências e não farão lances, pois podem usufruir os mesmos benefícios 
Contabilidade Pública como instrumento de previsão do Índice de Desenvolvimento Humano na dimensão Renda para os municípios do

Estado do Paraná

Jorge Eduardo Scarpin, Valmor Slomski

independente do pagamento ou dos lances que determinem". Como, nesse caso, o sistema de mercado não funciona, a alocação de recursos para o fornecimento desses bens é da alçada de uma decisão política.

Wonnacott e Wonnacott (1994, p.94) expõem que o "governo afeta a economia de quatro maneiras básicas: despesas, impostos, controles e empresas estatais". As decisões do governo em gastar, taxar, regular ou estabelecer uma empresa estatal influenciam diretamente, afinal as decisões são pautadas pela ótica de quais produtos e serviços serão produzidos pela economia, como e para quem.

A expansão dos gastos públicos se relaciona com o seu papel de produção dos bens públicos e de controle de externalidades numa economia de mercado, visto que, como explica Rezende (2000, p.119), "dada a incapacidade de os mercados organizarem-se eficientemente para produzir os bens públicos, os governos tendem a permanecer se expandindo".

A intervenção governamental pelas despesas públicas é dada por duas vias. A primeira delas é o bem público, propriamente dito, que não pode ser feito pelo mercado, como é o caso da segurança pública. Também existem os bens públicos para a produção de externalidades positivas, como é o caso de uma campanha de vacinação, visto que quando se imuniza a população contra uma doença transmissível há um grande benefício implícito que é a segurança de que a população não sofrerá da doença.

\subsection{Renda e Desenvolvimento Humano}

A determinante renda é crucial no desenvolvimento humano, visto que, quanto maior a renda da população, mais recursos são arrecadados pelo Estado na forma de impostos e, com isto, um maior gasto pode ser realizado nas funções econômicas básicas.

Todavia muitos países enfrentaram séculos de estagnação da renda per capita, o que pode indicar que a pobreza pode representar um equilíbrio estável. Simonsen e Cysne (1995, p.498) explicam o fenômeno pela "insuficiência da 
Contabilidade Pública como instrumento de previsão do Índice de Desenvolvimento Humano na dimensão Renda para os municípios do

Estado do Paraná

Jorge Eduardo Scarpin, Valmor Slomski

formação de capital diante do crescimento populacional: um país é pobre porque poupa pouco, poupa pouco porque é pobre". Esta teoria foi apelidada pelos economistas de "teoria do círculo vicioso da pobreza". E é diante da formação de capital que está a chave para a diminuição da pobreza.

No Brasil, a renda média é afetada principalmente pela desigualdade entre a renda dos mais ricos e dos mais pobres. O primeiro trabalho a ser apresentado sobre crescimento e desigualdade da distribuição de renda foi o clássico paper de Kuznets (1955). No Brasil, diversos trabalhos têm enfocado o tema. Hoffmann (1995) analisa as relações entre pobreza absoluta, renda média e desigualdade da distribuição de renda, mas não obtém valores das elasticidades da pobreza em relação às outras duas variáveis. Equações de regressão relacionando essas variáveis com base em dados sincrônicos ou séries temporais são apresentadas nesse trabalho e também em Hoffmann (1992 e 1998). Barros e Mendonça (1997) desenvolveram importante análise comparativa entre os impactos do crescimento econômico e de reduções na desigualdade sobre o grau de pobreza no Brasil.

\section{METODOLOGIA}

Para Rudio (2000, p. 9), "a fim de merecer o qualitativo de científica, a pesquisa deve ser feita de modo sistematizado, utilizando, para isto, método próprio e técnicas específicas e procurando um conhecimento que se refira à realidade empírica. " Realidade empírica para o autor é "tudo que existe e pode ser conhecido através da experiência".

Neste trabalho, a busca de resposta à questão-problema deu-se, fundamentalmente, por meio de pesquisa explicativa. Segundo Gil (1999), a pesquisa explicativa tem como principal objetivo identificar os fatores que determinam ou contribuem para a ocorrência dos fenômenos. Por explicar a razão e o porquê das coisas, esse é o tipo de pesquisa que mais aprofunda o conhecimento da realidade.

Raupp e Beuren (2003, p. 82) explicam que "a pesquisa explicativa integra 
Contabilidade Pública como instrumento de previsão do Índice de Desenvolvimento Humano na dimensão Renda para os municípios do

Estado do Paraná

Jorge Eduardo Scarpin, Valmor Slomski

estudos mais aprofundados pela necessidade de explicar os determinantes na ocorrência dos fenômenos". A hipótese geral que delimita o campo desta pesquisa é:

H0: as informações provenientes da contabilidade pública possuem valor preditivo na determinação do IDH-M na função renda dos municípios do Estado do Paraná.

A abordagem da pesquisa é de natureza quantitativa-qualitativa. A quantitativa foi utilizada para desenvolver a modelagem matemática para determinar as variáveis contábeis que possuem relação com o IDH-M na dimensão renda, evidenciar a temporalidade das informações contábeis no IDH-M na dimensão renda, bem como prever valores futuros do IDH-M na dimensão renda com base em variáveis contábeis. Por sua vez, a abordagem qualitativa foi adotada para dar base e parametrizar os resultados quantitativos, visando a uma melhor análise geral do caso.

A presente pesquisa deu-se por meio de uma pesquisa documental. Segundo Lakatos e Marconi (2001, p. 174), "a característica da pesquisa documental é que a fonte de coleta de dados está restrita a documentos, escritos ou não, constituindo o que se denomina de fontes primárias".

A pesquisa deu-se pelo cruzamento dos dados do IDH-M na dimensão renda no ano de 2000, disponível no software Atlas do Desenvolvimento Humano do Brasil - versão 1.0.0, com dados de variáveis contábeis municipais disponíveis no site do Tesouro Nacional, por meio do software Finanças do Brasil (Finbra), bem como por outras informações não contábeis, disponíveis no software Atlas do Desenvolvimento Humano do Brasil - versão 1.0.0, no Instituto Brasileiro de Geografia e Estatística (IBGE), no Instituto Paranaense de Desenvolvimento Econômico e Social (IPARDES) e também no site do Governo do Estado do Paraná. Ressalte-se que o IDH-M na dimensão renda foi calculado com base nos dados apurados diretamente dos Censos Demográficos de 1991 e 2000 
Contabilidade Pública como instrumento de previsão do Índice de Desenvolvimento Humano na dimensão Renda para os municípios do

Estado do Paraná

Jorge Eduardo Scarpin, Valmor Slomski

(questionário da amostra), do IBGE.

A população desta pesquisa é composta pelos 398 municípios do Estado do Paraná. Para a amostra, foram extraídos 370 municípios. Os 28 municípios restantes foram excluídos da amostra, visto não haver a possibilidade da obtenção dos seus dados para as variáveis contábeis.

A técnica estatística selecionada para o objetivo deste trabalho foi análise de regressão. Através desta técnica foi possível calcular o nível de sensibilidade entre as informações contábeis e o índice de desenvolvimento humano municipal (IDHM). Ressalte-se que, para todos os testes estatísticos, foi utilizado um nível de significância de $5 \%$.

De acordo com a hipótese elaborada, foram selecionadas 01 variável dependente e 83 variáveis independentes para a pesquisa. A variável dependente foi baseada nos valores do IDH-M na dimensão renda do ano de 2000. Para explicar as variáveis dependentes, foram selecionadas 83 variáveis independentes, considerando-se variáveis contábeis e não contábeis para o aprofundamento do estudo em questão. Como os municípios possuem populações de tamanhos muito díspares, há o problema de escala, havendo necessidade de ajustar algumas variáveis pelo tamanho da população, trabalhando com seu valor per capita.

As variáveis não contábeis utilizadas no modelo são: IDH-M de 1991 em todas as suas dimensões; Altitude; Densidade Demográfica em 2000; Distância à Capital; População Rural nos anos de 1991 e 2000; População Urbana nos anos de 1991 e 2000 e a Taxa de Variação da População Total entre os anos de 1991 e 2000. Por sua vez, as variáveis contábeis utilizadas no modelo são as receitas e despesas públicas de 1997 a 2000.

Todo tipo de pesquisa possui limitações. Marconi e Lakatos (1999, p. 31) afirmam que um dos limites para a investigação é que "nem sempre se pode abranger todo o âmbito no qual o fato se desenrola". As principais limitações desta pesquisa baseiam-se no fato que o Atlas do Desenvolvimento Humano do Brasil traz os índices de desenvolvimento humano municipal nos anos de 2000 e 1991, não sendo possível, portanto traçar uma longa série histórica; e que a pesquisa se 
Contabilidade Pública como instrumento de previsão do Índice de Desenvolvimento Humano na dimensão Renda para os municípios do

Estado do Paraná

Jorge Eduardo Scarpin, Valmor Slomski

restringirá ao Estado do Paraná. Em virtude disto, seus resultados não poderão ser extrapolados para o restante dos Estados da Federação.

Apesar dessas limitações, as conclusões obtidas por meio do estudo cuidadoso e de critérios científicos adotados no desenvolvimento do trabalho, todavia, não são invalidadas por essas limitações, sendo possível a conclusão sobre a relevância da informação contábil no índice de desenvolvimento humano municipal na dimensão renda, bem como a sua predição com base nas variáveis contábeis.

\section{RESULTADOS DA PESQUISA}

Nesta seção serão apresentados os resultados da pesquisa para os modelos de previsão de IDH-M na dimensão renda futuro, com a análise dos modelos de regressão para estimar quais variáveis independentes, com suas respectivas temporalidades, impactam o IDH-M na dimensão renda futuro.

Analisando os modelos de regressão com todas as variáveis independentes, pelo método Stepwise, foram obtidos sete possíveis modelos.

\subsection{Modelo 01}

O primeiro modelo testado possui como variável independente apenas o Índice de Desenvolvimento Humano Municipal total do ano de 1991, sem considerar nenhuma outra variável.

Em relação aos pressupostos, os testes para a heterocedasticidade, multicolinearidade, autocorrelação serial e normalidade dos resíduos tiveram resultados satisfatórios.

As estatísticas da regressão para este modelo constam na Tabela a seguir.

Tabela 1. Estatísticas do modelo 01 - IDH-M Renda

\begin{tabular}{c|c|c|c}
\hline $\mathbf{R}$ & $\begin{array}{c}\mathbf{R} \\
\text { quadrado }\end{array}$ & $\begin{array}{c}\mathbf{R} \text { quadrado } \\
\text { ajustado }\end{array}$ & $\begin{array}{c}\text { Erro padrão da } \\
\text { regressão }\end{array}$ \\
\hline 0,84 & 0,714 & 0,713 & $2,4901 \mathrm{E}-02$ \\
\hline
\end{tabular}

O modelo mostra-se com um coeficiente de determinação ajustado bastante significativo, que explica $71,3 \%$ do IDH-M futuro. 
Contabilidade Pública como instrumento de previsão do Índice de Desenvolvimento Humano na dimensão Renda para os municípios do

Estado do Paraná

Jorge Eduardo Scarpin, Valmor Slomski

No resultado da ANOVA, o modelo apresentou-se com a rejeição da hipótese nula dos coeficientes das variáveis independentes em conjunto serem iguais a zero, com um valor do teste F igual a 919,700 e com Sig igual a 0,000.

Os coeficientes da regressão para este modelo apresentaram os resultados e estatísticas constantes na tabela a seguir.

Tabela 2. Coeficientes - modelo 01 - IDH-M Renda

\begin{tabular}{l|c|c|c|c}
\hline \multicolumn{1}{c|}{ Coeficientes } & Beta & Std. Error & T & Sig \\
\hline $\begin{array}{l}\text { (Constant) } \\
\begin{array}{l}\text { Indice de Desenvolvimento Humano Municipal } \\
-1991\end{array}\end{array}$ & $6,793 \mathrm{E}-02$ & 0,019 & 3,506 & 0,001 \\
\hline
\end{tabular}

Os índices apresentaram relevâncias estatísticas boas, com Sig inferior a $5 \%$. Em relação aos coeficientes, o modelo apresentou a seguinte fórmula para previsão do IDH-M futuro na dimensão renda:

IDH-M Renda $2000=6,793 \mathrm{E}-02+0,887$ * IDH-M total

Pela fórmula evidencia-se que o IDH na dimensão renda futuro será apenas $88,70 \%$ do IDH- $M$ total passado, o que mostra uma relação bem próxima deste indicador. Ressalte-se também que foi o menor valor encontrado pela constante em todos os modelos aqui testados até o momento.

\subsection{Modelo 02}

O segundo modelo testado possui como variável independente, o Índice de Desenvolvimento Humano Municipal total do ano de 1991 e o Índice de Desenvolvimento Humano Municipal na dimensão Longevidade do ano de 1991, sem considerar nenhuma outra variável.

Em relação aos pressupostos, os testes para a heterocedasticidade, autocorrelação serial e normalidade dos resíduos tiveram resultados satisfatórios.

Em relação a multicolinearidade das variáveis independentes, foi verificada a 
Contabilidade Pública como instrumento de previsão do Índice de Desenvolvimento Humano na dimensão Renda para os municípios do

Estado do Paraná

Jorge Eduardo Scarpin, Valmor Slomski

multicolinearidade, sendo que o coeficiente de correlação de Pearson para as variáveis é igual a 0,689.

As estatísticas da regressão para este modelo constam na tabela a seguir.

Tabela 3. Estatísticas do modelo 02 - IDH-M Renda

\begin{tabular}{c|c|c|c}
\hline $\mathbf{R}$ & $\mathbf{R}$ quadrado & $\mathbf{R}$ quadrado ajustado & $\begin{array}{c}\text { Erro padrão da } \\
\text { regressão }\end{array}$ \\
\hline 0,884 & 0,782 & 0,780 & $2,1802 \mathrm{E}-02$ \\
\hline
\end{tabular}

O modelo mostra-se com um coeficiente de determinação ajustado bastante significativo, que explica 78,0\% do IDH-M futuro.

No resultado da ANOVA, o modelo apresentou-se com a rejeição da hipótese nula dos coeficientes das variáveis independentes em conjunto serem iguais a zero, com um valor do teste F igual a 656,423 e com Sig igual a 0,000.

Os coeficientes da regressão para este modelo apresentaram os resultados e estatísticas constantes na tabela a seguir.

Tabela 4. Coeficientes - modelo 02 - IDH-M Renda

\begin{tabular}{|c|c|c|c|c|}
\hline Coeficientes & Beta & Std. Error & $T$ & Sig \\
\hline$\overline{\text { (Constant) }}$ & 0,139 & 0,018 & 7,622 & 0,000 \\
\hline İndice de Desenvolvimento Humano Municipal 1991 & 1,146 & 0,035 & 32,437 & 0,000 \\
\hline Indice de Desenvolvimento Humano Municipal-Long. 1991 & $-0,363$ & 0,034 & $-10,633$ & 0,000 \\
\hline
\end{tabular}

Os índices apresentaram relevâncias estatísticas boas, com Sig inferior a $5 \%$. Ressalte-se que a constante ficou mais alta em relação ao modelo anterior e, talvez devido à multicolinearidade, tenha havido uma transferência da previsão para o IDH-M total, ao colocar o IDH-M na dimensão longevidade com um coeficiente negativo. Em relação aos coeficientes, o modelo apresentou a seguinte fórmula para previsão do IDH-M futuro na dimensão renda:

IDH-M-Renda $2000=0,139+1,146$ * IDH-M total $-0,363$ * IDH-M Longevidade

Pela fórmula evidencia-se que o IDH-M na dimensão longevidade futura está distribuído com mais intensidade na constante e mais intensidade no IDH-M total, 
Contabilidade Pública como instrumento de previsão do Índice de Desenvolvimento Humano na dimensão Renda para os municípios do

Estado do Paraná

Jorge Eduardo Scarpin, Valmor Slomski

mas compensado com um coeficiente negativo no IDH-M na dimensão Longevidade.

\subsection{Modelo 03}

O terceiro modelo testado possui como variável independente o Índice de Desenvolvimento Humano Municipal total do ano de 1991, o Índice de Desenvolvimento Humano Municipal na dimensão Longevidade do ano de 1991 e o percentual da população rural no ano de 2000, sem considerar nenhuma outra variável.

Em relação aos pressupostos, os testes para a heterocedasticidade, autocorrelação serial e normalidade dos resíduos tiveram resultados satisfatórios.

Em relação a multicolinearidade das variáveis independentes, foi verificada a multicolinearidade também com a nova variável, com correlação negativa entre a população do ano de 2000 com o IDH-M na sua forma total.

As estatísticas da regressão para este modelo constam na tabela a seguir.

Tabela 5. Estatísticas do modelo 03 - IDH-M Renda

\begin{tabular}{c|c|c|c}
\hline $\mathbf{R}$ & $\mathbf{R}$ quadrado & $\mathbf{R}$ quadrado ajustado & $\begin{array}{c}\text { Erro padrão da } \\
\text { regressão }\end{array}$ \\
\hline 0,891 & 0,795 & 0,793 & $2,1164 \mathrm{E}-02$ \\
\hline
\end{tabular}

O modelo mostra-se com um coeficiente de determinação ajustado bastante significativo, que explica $79,3 \%$ do IDH-M futuro.

No resultado da ANOVA, o modelo apresentou-se com a rejeição da hipótese nula dos coeficientes das variáveis independentes em conjunto serem iguais a zero, com um valor do teste $F$ igual a 472,214 e com Sig igual a 0,000.

Os coeficientes da regressão para este modelo apresentaram os resultados e estatísticas constantes na tabela a seguir.

Tabela 6. Coeficientes - modelo 03 - IDH-M Renda

\begin{tabular}{l|c|c|c|c}
\hline \multicolumn{1}{c|}{ Coeficientes } & Beta & Std. Error & \multicolumn{1}{c|}{ S } & Sig \\
\hline (Constant) & 0,199 & 0,022 & 9,210 & 0,000 \\
\hline Indice de Desenvolvimento Humano Municipal 1991 & 1,017 & 0,043 & 23,424 & 0,000 \\
\hline Indice de Desenvolvimento Humano Municipal-Long. 1991 & $-0,307$ & 0,035 & $-8,762$ & 0,000 \\
\hline População rural 2000 & $-3,166 \mathrm{E}-02$ & 0,007 & $-4,843$ & 0,000 \\
\hline
\end{tabular}


Contabilidade Pública como instrumento de previsão do Índice de Desenvolvimento Humano na dimensão Renda para os municípios do

Estado do Paraná

Jorge Eduardo Scarpin, Valmor Slomski

Os índices apresentaram relevâncias estatísticas boas, com Sig inferior a $5 \%$. Ressalte-se que a constante ficou praticamente estável em relação ao modelo anterior, o que mostra uma transferência da previsão entre as variáveis. Em relação aos coeficientes, o modelo apresentou a seguinte fórmula para previsão do IDH-M futuro na dimensão renda:

IDH-M-Renda $2000=0,199+1,017 *$ IDH-M Total $-0,307 *$ IDH-M

Longevidade $-3,166 \mathrm{E}-02$ *

População Rural 2000

Pela fórmula evidencia-se que o IDH-M na dimensão renda futuro está distribuído com mais intensidade na constante, tendo relação positiva com o IDHM total e negativa com o IDH-M na dimensão longevidade. Há também a variável população rural em 2000, com um índice pequeno, porém negativo, o que mostra que a renda no campo é um fator que causa queda no IDH-M Renda, ou seja, cidades com população rural maior tem menos renda do que cidades com maior população urbana.

\subsection{Modelo 04}

O quarto modelo testado possui como variável independente o Índice de Desenvolvimento Humano Municipal total do ano de 1991, o Índice de Desenvolvimento Humano Municipal na dimensão Longevidade do ano de 1991, o percentual da população rural no ano de 2000 e a Receita Tributária do ano de 2000, sem considerar nenhuma outra variável.

Em relação aos pressupostos, os testes para a heterocedasticidade, autocorrelação serial e normalidade dos resíduos tiveram resultados satisfatórios.

Em relação a multicolinearidade das variáveis independentes, a adição da nova variável não trouxe problemas adicionais, ao modelo.

As estatísticas da regressão para este modelo constam na tabela a seguir. 
Contabilidade Pública como instrumento de previsão do Índice de Desenvolvimento Humano na dimensão Renda para os municípios do

Estado do Paraná

Jorge Eduardo Scarpin, Valmor Slomski

Tabela 7. Estatísticas do modelo 04 - IDH-M Renda

\begin{tabular}{c|c|c|c}
\hline $\mathbf{R}$ & $\mathbf{R}$ quadrado & $\mathbf{R}$ quadrado ajustado & $\begin{array}{c}\text { Erro padrão da } \\
\text { regressão }\end{array}$ \\
\hline 0,896 & 0,802 & 0,800 & $2,0790 \mathrm{E}-02$ \\
\hline
\end{tabular}

O modelo mostra-se com um coeficiente de determinação ajustado bastante significativo, que explica $80,0 \%$ do IDH-M futuro.

No resultado da ANOVA, o modelo apresentou-se com a rejeição da hipótese nula dos coeficientes das variáveis independentes em conjunto serem iguais a zero, com um valor do teste F igual a 370,602 e com Sig igual a 0,000.

Os coeficientes da regressão para este modelo apresentaram os resultados e estatísticas constantes na tabela a seguir.

Tabela 8. Coeficientes - modelo 04 - IDH-M Renda

\begin{tabular}{l|c|c|c|c}
\hline \multicolumn{1}{c|}{ Coeficientes } & Beta & Std. Error & T & Sig \\
& & & & \\
\hline (Constant) & 0,215 & 0,022 & 9,923 & 0,000 \\
\hline Indice de Desenvolvimento Humano Municipal 1991 & 0,946 & 0,047 & 20,314 & 0,000 \\
\hline Indice de Desenvolvimento Humano Municipal-Long. 1991 & $-0,268$ & 0,036 & $-7,468$ & 0,000 \\
\hline População rural 2000 & $-2,796 \mathrm{E}-02$ & 0,006 & $-4,304$ & 0,000 \\
\hline Receita Tributária 2000 & $1,321 \mathrm{E}-04$ & 0,000 & 3,781 & 0,000 \\
\hline
\end{tabular}

Os índices apresentaram relevâncias estatísticas boas, com Sig inferior a 5\%. Ressalte-se que a constante ficou praticamente estável em relação ao modelo anterior, o que mostra uma transferência da previsão entre as variáveis. Em relação aos coeficientes, o modelo apresentou a seguinte fórmula para previsão do IDH-M futuro na dimensão renda:

IDH-M-Renda $2000=0,215+0,946$ * IDH-M Total $-0,268$ * IDH-M Longevidade $-2,796 \mathrm{E}-02$ * População Rural $2000+1,321 \mathrm{E}-04$ * Receita Tributária 2000

Pela fórmula evidencia-se que o IDH-M na dimensão renda futuro está distribuído com mais intensidade na constante, tendo relação positiva com o IDHM total e negativa com o IDH-M na dimensão longevidade. Há também a variável 
Contabilidade Pública como instrumento de previsão do Índice de Desenvolvimento Humano na dimensão Renda para os municípios do

Estado do Paraná

Jorge Eduardo Scarpin, Valmor Slomski

população rural em 2000, com um índice pequeno, porém negativo, o que mostra que a renda no campo é um fator que causa queda no IDH-M Renda, ou seja, cidades com população rural maior tem menos renda do que cidades com maior população urbana. Como variável contábil, há o relacionamento positivo com a variável Receita Tributária no ano de 2000.

\subsection{Modelo 05}

O quinto modelo testado possui como variável independente o Índice de Desenvolvimento Humano Municipal total do ano de 1991, o Índice de Desenvolvimento Humano Municipal na dimensão Longevidade do ano de 1991, o percentual da população rural no ano de 2000, a Receita Tributária do ano de 2000 e a Despesa com Agricultura do ano de 1997, sem considerar nenhuma outra variável.

Em relação aos pressupostos, o primeiro testado foi o pressuposto da ausência de heterocedasticidade. Pelo teste de Pesaran e Pesaran, se rejeita a hipótese nula de ausência de heterocedasticidade, com um valor do teste $\mathrm{F}$ igual a 1,461 e com Sig igual a 0,228.

Houve a tentativa de transformação das variáveis, o que não resolveu o problema. O problema pode ter sido ocasionado pela omissão de variáveis independentes, fazendo com que o erro ficasse relacionado. Em virtude disto, este modelo não será utilizado.

\subsection{Modelo 06}

O sexto modelo a ser testado possui como variável independente o Índice de Desenvolvimento Humano Municipal total do ano de 1991, o Índice de Desenvolvimento Humano Municipal na dimensão Longevidade do ano de 1991, o percentual da população rural no ano de 2000, a Receita Tributária do ano de 2000, a Despesa com Agricultura do ano de 1997 e Despesas com Juros e Encargos da Dívida do ano de 1998, sem considerar nenhuma outra variável.

Em relação aos pressupostos, os testes para a heterocedasticidade, 
Contabilidade Pública como instrumento de previsão do Índice de Desenvolvimento Humano na dimensão Renda para os municípios do

Estado do Paraná

Jorge Eduardo Scarpin, Valmor Slomski

autocorrelação serial e normalidade dos resíduos tiveram resultados satisfatórios.

Em relação a multicolinearidade das variáveis independentes, a inclusão das novas variáveis não trouxe problemas adicionais ao modelo.

As estatísticas da regressão para este modelo constam na tabela a seguir.

Tabela 9. Estatísticas do modelo 06 - IDH-M Renda

\begin{tabular}{c|c|c|c}
\hline $\mathbf{R}$ & $\mathbf{R}$ quadrado & $\mathbf{R}$ quadrado ajustado & $\begin{array}{c}\text { Erro padrão da } \\
\text { regressão }\end{array}$ \\
\hline 0,903 & 0,815 & 0,812 & $2,019 \mathrm{E}-02$ \\
\hline
\end{tabular}

O modelo mostra-se com um coeficiente de determinação ajustado bastante significativo, que explica $81,2 \%$ do IDH-M futuro.

No resultado da ANOVA, o modelo apresentou-se com a rejeição da hipótese nula dos coeficientes das variáveis independentes em conjunto serem iguais a zero, com um valor do teste F igual a 265,903 e com Sig igual a 0,000.

Os coeficientes da regressão para este modelo apresentaram os resultados e estatísticas constantes na tabela a seguir.

Tabela 10. Coeficientes - modelo 06 - IDH-M Renda

\begin{tabular}{l|c|c|c|c}
\hline \multicolumn{1}{c|}{ Coeficientes } & Beta & $\begin{array}{c}\text { Std. } \\
\text { Error }\end{array}$ & T & Sig \\
\hline (Constant) & 0,234 & 0,021 & 10,925 & 0,000 \\
\hline Indice de Desenvolvimento Humano Municipal 1991 & 0,916 & 0,046 & 20,016 & 0,000 \\
\hline Indice de Desenvolvimento Humano Municipal-Long. 1991 & $-0,272$ & 0,035 & $-7,771$ & 0,000 \\
\hline População rural 2000 & $-3,319 \mathrm{E}-02$ & 0,007 & $-4,999$ & 0,000 \\
\hline Receita Tributária 2000 & $1,287 \mathrm{E}-04$ & 0,000 & 3,776 & 0,000 \\
\hline Agricultura 1997 & $2,791 \mathrm{E}-04$ & 0,000 & 3,382 & 0,001 \\
\hline Juros e Encargos da Dívida 1998 & $4,641 \mathrm{E}-04$ & 0,000 & 3,182 & 0,002 \\
\hline
\end{tabular}

Os índices apresentaram relevâncias estatísticas boas, com Sig inferior a $5 \%$, porém as duas últimas variáveis a serem adicionadas apresentaram uma significância diferente de zero. Ressalte-se que a constante ficou praticamente estável em relação ao modelo anterior, o que mostra uma transferência da previsão entre as variáveis. Em relação aos coeficientes, o modelo apresentou a seguinte fórmula para previsão do IDH-M futuro na dimensão renda: 
Contabilidade Pública como instrumento de previsão do Índice de Desenvolvimento Humano na dimensão Renda para os municípios do

Estado do Paraná

Jorge Eduardo Scarpin, Valmor Slomski

IDH-M-Renda $2000=0,234+0,916 *$ IDH-M Total $-0,272 *$ IDH-M Longevidade 3,319E-02 * População

Em relação aos pressupostos, os testes para a heterocedasticidade, autocorrelação serial e normalidade dos resíduos tiveram resultados satisfatórios.

Em relação a multicolinearidade das variáveis independentes, a inclusão da variável de altitude da sede não alterou a multicolinearidade, ficando apenas com os problemas das variáveis anteriores.

As estatísticas da regressão para este modelo constam na tabela a seguir.

Tabela 11. Estatísticas do modelo 07 - IDH-M Renda

\begin{tabular}{c|c|c|c}
\hline $\mathbf{R}$ & $\mathbf{R}$ quadrado & $\mathbf{R}$ quadrado ajustado & $\begin{array}{c}\text { Erro padrão da } \\
\text { regressão }\end{array}$ \\
\hline 0,904 & 0,817 & 0,814 & $2,008 \mathrm{E}-02$ \\
\hline
\end{tabular}

O modelo mostra-se com um coeficiente de determinação ajustado bastante significativo, que explica $81,4 \%$ do IDH-M futuro.

No resultado da ANOVA, o modelo apresentou-se com a rejeição da hipótese nula dos coeficientes das variáveis independentes em conjunto serem iguais a zero, com um valor do teste F igual a 231,261 e com Sig igual a 0,000.

Os coeficientes da regressão para este modelo apresentaram os resultados e estatísticas constantes na tabela a seguir.

Tabela 12. Coeficientes - modelo 07 - IDH-M total

\begin{tabular}{|c|c|c|c|c|}
\hline Coeficientes & Beta & $\begin{array}{l}\text { Std. } \\
\text { Error }\end{array}$ & $T$ & Sig \\
\hline (Constant) & 0,238 & 0,021 & 11,146 & 0,000 \\
\hline İndice de Desenvolvimento Humano Municipal 1991 & 0,903 & 0,046 & 19,706 & 0,000 \\
\hline Indice de Desenvolvimento Humano Municipal-Longev. 1991 & $-0,259$ & 0,035 & $-7,382$ & 0,000 \\
\hline População rural 2000 & $-3,454 \mathrm{E}-02$ & 0,007 & $-5,211$ & 0,000 \\
\hline Receita Tributária 2000 & 1,329E-04 & 0,000 & 3,914 & 0,000 \\
\hline Agricultura 1997 & 3,687E-04 & 0,000 & 4,049 & 0,000 \\
\hline Juros e Encargos da Dívida 1998 & 4,822E-04 & 0,000 & 3,320 & 0,001 \\
\hline Saúde e Saneamento 1997 & $-9,722 E-05$ & 0,000 & $-2,270$ & 0,024 \\
\hline
\end{tabular}

Os índices apresentaram relevâncias estatísticas boas, com Sig inferior a $5 \%$, porém as duas últimas variáveis a serem adicionadas apresentaram uma 
Contabilidade Pública como instrumento de previsão do Índice de Desenvolvimento Humano na dimensão Renda para os municípios do

Estado do Paraná

Jorge Eduardo Scarpin, Valmor Slomski

significância diferente de zero. Ressalte-se que a constante ficou praticamente estável em relação ao modelo anterior, o que mostra uma transferência da previsão entre as variáveis. Em relação aos coeficientes, o modelo apresentou a seguinte fórmula para previsão do IDH-M futuro na dimensão renda:

IDH-M-Renda $2000=0,238+0,913$ * IDH-M Total $-0,259 *$ IDH-M Longevidade $-3,454 \mathrm{E}-02$ * População Rural $2000+1,329 \mathrm{E}-04$ * Receita Tributária $2000+3,687 \mathrm{E}-04$ * Despesa com Agricultura $1997+4,822 \mathrm{E}-04$ * Juros e Encargos da Dívida 1998 - 9,722E-05 * Saúde e Saneamento 1997

Pela fórmula evidencia-se que o IDH-M na dimensão renda futuro está distribuído com mais intensidade na constante, tendo relação positiva com o IDH-M total e negativa com o IDH-M na dimensão longevidade. Há também a variável população rural em 2000, com um índice pequeno, porém negativo, o que mostra que a renda no campo é um fator que causa queda no IDH-M Renda, ou seja, cidades com população rural maior tem menos renda do que cidades com maior população urbana. Entretanto, um fator paliativo é o relacionamento positivo com a Despesa com Agricultura de 1997, o que pode fazer com que a renda da população rural aumente. Como variável contábil, há o relacionamento positivo com a variável Receita Tributária no ano de 2000 , além do relacionamento positivo com Juros e Encargos da Dívida de 1998, além da despesa com agricultura já citada. Finalmente, há o relacionamento negativo com a variável de Saúde e Saneamento 1997, o que, aparentemente, é uma relação espúria, visto que não há uma relação de negatividade aparente entre estes itens.

\section{CONCLUSÃO SOBRE OS MODELOS DE PREVISÃO DO IDH-M RENDA}

Foram encontrados seis modelos que satisfizeram as condições previstas nos testes de regressão. Os modelos variaram desde uma regressão simples até um modelo com sete variáveis independentes. Ressalte-se que um modelo encontrado apresentou heterocedasticidade.

O modelo que mais bem se ajustou foi o modelo de número 07 , obtendo um 
Contabilidade Pública como instrumento de previsão do Índice de Desenvolvimento Humano na dimensão Renda para os municípios do

Estado do Paraná

Jorge Eduardo Scarpin, Valmor Slomski

coeficiente de determinação ajustado de 0,814 , ou seja, as variáveis independentes explicam $81,4 \%$ da variável dependente.

As variáveis utilizadas no modelo mais completo foram: Índice de Desenvolvimento Humano Municipal total do ano de 1991, o Índice de Desenvolvimento Humano Municipal na dimensão Longevidade do ano de 1991, o percentual da população rural no ano de 2000, a Receita Tributária do ano de 2000, a Despesa com Agricultura do ano de 1997, Despesas com Juros e Encargos da Dívida do ano de 1998 e Despesa com Saúde e Saneamento do ano de 1997.

Para a previsão do IDH-M renda futuro foram encontradas mais variáveis contábeis do que variáveis não contábeis para a composição da fórmula global. Isto é explicado devido ao fato que a dimensão renda tem maior relação com receitas e despesas do município. As quatro variáveis contábeis relevantes foram a receita tributária do ano corrente, a despesa com agricultura com defasagem de 04 anos, despesas com juros e encargos da dívida com defasagem de 03 anos e despesa com saúde e saneamento com defasagem de 04 anos.

A fórmula para a previsão do IDH-M na dimensão renda futuro ficou assim definida:

IDH-M-Renda $2000=0,238+0,913 *$ IDH-M Total $-0,259 *$ IDH-M Longevidade $-3,454 \mathrm{E}-02$ * População Rural $2000+1,329 \mathrm{E}-04$ * Receita Tributária $2000+3,687 \mathrm{E}-04$ * Despesa com Agricultura 1997 + 4,822E-04 * Juros e Encargos da Dívida 1998 - 9,722E-05 * Saúde e Saneamento 1997

Além das conclusões matemáticas expressas no item anterior, a fórmula leva a algumas conclusões importantes:

$\mathrm{O}$ IDH-M na dimensão renda futuro é fortemente influenciado pelo IDH-M passado, tanto no total quanto na dimensão longevidade, o que mostra que alterações no índice são possíveis apenas com planejamentos de longo prazo. Embora a dimensão longevidade tenha apresentado um valor negativo, tal fato se explica pela correlação entre os dois índices, o que faz com que os dados de cada 
Contabilidade Pública como instrumento de previsão do Índice de Desenvolvimento Humano na dimensão Renda para os municípios do

Estado do Paraná

Jorge Eduardo Scarpin, Valmor Slomski

um não sejam muito relevantes.

A variável população rural causou um comportamento negativo, o que mostra que a renda no campo é inferior à renda na cidade, fazendo com que municípios que apresentem uma alta população rural tenham um IDH-M menor do que municípios com alta população urbana. Tal fato é ruim, pois pode provocar um aumento no problema de êxodo rural. Entretanto, mais pesquisas são necessárias para um estudo profundo deste fenômeno.

As variáveis contábeis Receita Tributária corrente e Despesa com Agricultura com defasagem de 04 anos apresentaram comportamentos positivos, o que era esperado, pois, com maior receita e maior gasto há a tendência de haver uma melhora no desenvolvimento humano do município.

Por sua vez, a variável Juros e Encargos da Dívida com defasagem de 03 anos apresentou um comportamento positivo, ou seja, quanto mais se gasta neste item, menor o IDH-M na dimensão renda. Sobre este comportamento há uma chance de ser um relacionamento espúrio, visto que quanto mais se pagam de juros e encargos da dívida, menos recursos sobram para gastos em itens que elevariam a renda da população. Este relacionamento poderia ser explicado pelo fato que as cidades maiores terem um gasto maior com juros, sendo o aumento do IDH-M renda ser ocasionado não pelo gasto com juros em si, mas pelo porte da cidade.

Finalmente, a variável contábil Saúde e Saneamento com defasagem de 04 anos apresentou um comportamento negativo.

Em virtude disto, recomenda-se futuras pesquisas nos demais estados brasileiros para a verificação de uma congruência ou não dos resultados encontrados.

\section{REFERÊNCIAS}

Atlas do Desenvolvimento Humano do Brasil - versão 1.0.0. Software contendo os dados do IDH dos municípios brasileiros. 2003. Disponível em http://www.pnud.org.br/atlas, acesso em 25/02/2005.

GIL, A.C. 1999. Métodos e técnicas de pesquisa social. 5ª ed. São Paulo, Atlas, 206 p. 
Contabilidade Pública como instrumento de previsão do Índice de Desenvolvimento Humano na dimensão Renda para os municípios do

Estado do Paraná

Jorge Eduardo Scarpin, Valmor Slomski

GOVERNO DO ESTADO DO PARANÁ. Apresenta informações sobre o Estado do Paraná e sobre os municípios paranaenses. Disponível em http://www.pr.gov.br, acesso em 12/03/2005.

HOFFMANN, R. 1998. Desigualdade e pobreza no Brasil no perído 1979/97 e a influência da inflação e do salário mínimo. Economia e Sociedade, 11:199-221.

HOFFMANN, R. 1992. Desigualdade e pobreza no Brasil no período 1979-90. In: Encontro Brasileiro de Econometria, 14, Campos de Jordão. Anais..., p. 311-336. Revista Brasileira de Economia, 49(2):277-294.

HOFFMANN, R. 1995. Relações entre pobreza absoluta, renda média e desigualdade da distribuição de renda. Pesq. Plan. Econ., 25(2):337-358.

IBGE. Instituto Brasileiro de Geografia e Estatística. Apresenta informações sobre dados estatísticos nacionais. Disponível em http://www.ibge.gov.br, acesso em $21 / 03 / 2005$.

IPARDES. Instituto Paranaense de Desenvolvimento Econômico e Social. Apresenta informações sobre dados estatísticos do Estado do Paraná. Disponível em http://www.pr.gov.br/ipardes, acesso em 15/04/2005.

KON, A. 1997. Subsídios teóricos e metodológicos ao planejamento econômico público.

EAESP/FGV/NPP - Núcleo de Pesquisas e Publicações. Relatório de pesquisa, 12.

KUZNETS, S. 1955. Economic growth and income inequality. American Economic Review, 45. LAKATOS, E.M. e MARCONI, M. de A. 2001. Fundamentos de metodologia científica. $4^{\underline{a}}$ ed. São Paulo, Atlas, 288 p.

MANKIW, N.G. 2001. Introdução à economia: princípios de micro e macroeconomia. Rio de Janeiro, Campus, $831 \mathrm{p}$.

MARCONI, M. de A. e LAKATOS, E.M. 1999. Técnicas de pesquisa. 4⿳a ed. São Paulo, Atlas, $260 \mathrm{p}$.

MEDEIROS, M. 1999. Princípios de justiça na alocação de recursos em saúde. Texto para discussão oㅜ 687. IPEA - Instituto de Pesquisa Econômica Aplicada. Rio de Janeiro, dezembro.

PINDICK, R.S. e RUBINFELD, D.L. 1994. Microeconomia. São Paulo, Makron Books, $791 \mathrm{p}$.

RAUPP, F.M. e BEUREN, I.M. 2003. Metodologia da pesquisa aplicável às ciências 
Contabilidade Pública como instrumento de previsão do Índice de Desenvolvimento Humano na dimensão Renda para os municípios do

Estado do Paraná

Jorge Eduardo Scarpin, Valmor Slomski

sociais. In: I.M. BEUREN (org.). Como elaborar trabalhos monográficos em contabilidade: teoria e prática. São Paulo, Atlas.

REZENDE, F. da C. 2000. Organizações e respostas institucionais a políticas de reformas do estado: um estudo de caso na administração direta do executivo federal brasileiro. Revista de sociologia e política, 14.

RUDIO, F.V. 2000. Introdução ao projeto de pesquisa científica. Petrópolis, Vozes, 144 p. SIMONSEN, M.H. e CYSNE, R.P. 1995. Macroeconomia. $2^{-a}$ ed. São Paulo, Atlas, $696 \mathrm{p}$.

Tesouro Nacional: apresenta informações sobre as finanças municipais. Disponível em http://www.tesouro.fazenda.gov.br/estados_municipios/index.asp, acesso em 28/02/2005.

TORRES, H. da G.; FERREIRA, M.P. e DINI, N.P. 2003. Indicadores sociais: por que construir novos indicadores como o IPRS. São Paulo Perspec, 17(3-4).

WONNACOTT, P. e WONNACOTT, R. 1994. Economia. $2^{\underline{a}}$ ed. São Paulo, Makron Books, $833 \mathrm{p}$. 